\title{
Nitric Oxide Stimulates cGMP Production and Mimics Synaptic Responses in Metacerebral Neurons of Aplysia
}

\author{
Hae-Young Koh and Jon W. Jacklet \\ Department of Biological Sciences, University at Albany, State University of New York, Albany, New York 12222
}

Nitric oxide (NO) acts as a neurotransmitter and neuromodulator in the nervous systems of many vertebrates and invertebrates. We investigated the mechanism of $\mathrm{NO}$ action at an identified synapse between a mechanoafferent neuron, C2, and the serotonergic metacerebral cell (MCC) in the cerebral ganglion of the mollusc Aplysia californica. Stimulation of C2 produces a decreasing conductance, very slow EPSP in the MCC. C2 is thought to use histamine and NO as cotransmitters at this synapse, because both agents mimic the membrane responses. Now we provide evidence that treatment with $\mathrm{NO}$ donors stimulates soluble guanylyl cyclase (sGC) in the MCC, and as a result cGMP increases. S-Nitrosocysteine (SNC, an $\mathrm{NO}$ donor) and 8-bromo-cGMP (8-Br-cGMP) both induced the membrane depolarization and increase in input resistance that are characteristic of the very slow EPSP. Two inhibitors of SGC, 6-anilino-5,8-quinolinequinone (LY83583) and $1 \mathrm{H}$-[1,2,4]oxadiazolo[4,3-a]quinoxaline-1-one (ODQ), suppressed both the very slow EPSP and the membrane responses to SNC but not the histamine membrane responses. NO-induced cGMP production was determined in the MCC using cGMP immunocytochemistry (cGMP-IR). In the presence of 3-isobutyl-1methylxanthine (IBMX), $10 \mu \mathrm{M}$ SNC was sufficient to induce cGMP-IR, and the staining intensity increased as the SNC dose was increased. This cGMP-IR was suppressed by ODQ in a dose-dependent manner and completely blocked by $10 \mu \mathrm{M}$ ODQ. Histamine did not induce cGMP-IR. The results suggest that NO stimulates sGC-dependent cGMP synthesis in the MCC and that CGMP mediates the membrane responses. The cotransmitter histamine induces essentially the same membrane responses but seems to use a separate and distinct second messenger pathway.

Key words: Aplysia; cGMP; nitric oxide; soluble guanylyl cyclase; immunoreactivity; histamine; cotransmitters; synapses; EPSP
Nitric oxide (NO) is a versatile signaling molecule. Its roles in a variety of physiological functions in mammals (Bredt and Snyder, 1994) and invertebrates (Jacklet, 1997) are beginning to be understood, but there is much to be learned. Its performance as a neurotransmitter and neuromodulator is now established in the mammalian PNS (Rand and Li, 1995) and CNS (Schuman and Madison, 1994) and in the CNS of invertebrates, especially molluscs (Jacklet, 1995, 1997; Moroz and Gillette, 1996) and insects (Müller, 1997).

NO is a water-soluble free radical gas that readily diffuses through membranes and reacts with heme-containing proteins and other effector molecules. NO is produced from arginine by the $\mathrm{Ca}^{2+}$ /calmodulin-dependent enzyme nitric oxide synthase (NOS). NOS has been localized by NADPH diaphorase histochemistry in the mammalian nervous systems, and it has been shown that the distribution of NOS immunoreactivity is identical to that of NADPH diaphorase activity in central and peripheral mammalian tissues (Hope et al., 1991). This is true for many cases in invertebrate nervous systems as well.

Large identifiable neurons in the mollusc Aplysia have been used very successfully to identify the synaptic mechanisms involved in a variety of behaviors [e.g., feeding (Weiss et al., 1986b;

\footnotetext{
Received Nov. 16, 1998; revised Feb. 16, 1999; accepted Feb. 18, 1999.

We gratefully acknowledge support for this research from the National Institute of Mental Health Grant 1R01MH5774601A1 and from State University of New York Research Foundation funds. We thank Dr. Jan De Vente for providing the cGMP antiserum used in this study.

Correspondence should be addressed to Dr. Jon W. Jacklet, Department of Biological Sciences, University at Albany, State University of New York, Albany, NY 12222.

Copyright (C) 1999 Society for Neuroscience $0270-6474 / 99 / 193818-09 \$ 05.00 / 0$
}

Chiel et al., 1990) and learning (Lechner and Byrne, 1998)]. We have used identified neurons, $\mathrm{C} 2$ and its synaptic follower the metacerebral cell (MCC), to study the synaptic mechanisms of NO signaling, involving soluble guanylyl cyclase (sGC) and cGMP. C2 is a histaminergic mechanoafferent neuron and a multifunctional modulator in the feeding circuit (Chiel et al., 1986; Weiss et al., 1986a-c). Stimulation of it evokes a very slow EPSP (vsEPSP) in the MCC (McCaman and Weinreich, 1985). The vsEPSP diminishes without reversal, as the cell is hyperpolarized, and is associated with decreased membrane conductance, which seems to be mediated by decreased potassium conductance (Weiss et al., 1986a).

NO is thought to be a cotransmitter at the C2-MCC synapse because NADPH diaphorase histochemical treatment indicates that $\mathrm{C} 2$ contains NOS, and the MCC responds to the NO generators 3-morpholino-synonimine (SIN-1) and $S$-nitrosocysteine (SNC) by the membrane depolarization and decreased conductance that are characteristic of the vsEPSP (Jacklet, 1995). Furthermore, the vsEPSP is substantially reduced by the NOS inhibitors L-nitroarginine (L-NA) and L-nitroarginine methyl ester (LNAME) and by the NO scavenger reduced hemoglobin.

To understand how the cotransmitters histamine and NO contribute to the vsEPSP in the MCC, we investigated the second messenger system that was likely to be used. Soluble GC is the most common target for NO in many nervous systems (Garthwaite, 1991; Luo et al., 1994). The involvement of sGC and cGMP in the NO signaling was suggested by the preliminary finding that 8-bromo-cGMP (8-Br-cGMP) mimics the NO effects in the MCC (Koh and Jacklet, 1997). To determine whether NO signaling in the MCC is mediated by the sGC-cGMP pathway, 
we compared the effects of $\mathrm{NO}$ generators with those of $8-\mathrm{Br}$ cGMP on membrane responses and measured the NO-induced cGMP production in the MCC using cGMP immunocytochemistry (cGMP-IR). We also examined effects of sGC inhibitors on the evoked vsEPSP, the membrane response to NO generators, and NO-induced cGMP-IR.

\section{MATERIALS AND METHODS}

Animals and chemicals. Aplysia californica (100-150 gm) were supplied by Marinus (Long Beach, CA), kept in an aquarium tank at $16-20^{\circ} \mathrm{C}$, and fed dried seaweed. SNC stock solution $(100 \mathrm{mM})$ was made by dissolving $100 \mathrm{~mm}$ L-cysteine (C-7755; Sigma, St. Louis, MO) and $100 \mathrm{~mm}$ sodium nitrite (23721-3; Aldrich, Milwaukee, WI) in $959 \mu$ l of distilled water on ice and adding $41 \mu \mathrm{l}$ of $\mathrm{HCl}$ (12.1N; Fisher Scientific, Houston, TX), which makes the solution turn red. The stock solution was kept on ice and used within $2 \mathrm{hr}$ (Lei et al., 1992). Histamine (50 mM; hydrochloric form, $\mathrm{H}-7250$; Sigma) in artificial seawater (ASW) was freshly made for each experiment and kept at $4^{\circ} \mathrm{C}$. 8-Br-cGMP (sodium salt, B-1381; Sigma) was dissolved in distilled water to $5 \mathrm{~mm}$ and stored in a freezer $\left(-20^{\circ} \mathrm{C}\right)$; 20 mM 6-anilino-5,8-quinolinequinone (LY83583; 440205; Calbiochem, La Jolla, CA), $20 \mathrm{~mm} 1 H$-[1,2,4]oxadiazolo[4,3-a]quinoxaline-1-one (ODQ; 0880; Tocris Cookson), and 0.5 m 3-isobutyl-1-methylxanthine (IBMX; 410957; Calbiochem) stock solutions were made in DMSO (dimethylsulfoxide; D-128; Fisher Scientific) and kept frozen at $-20^{\circ} \mathrm{C}$.

Electrophysiology. Isolated cerebral ganglia were incubated in $1 \%$ protease (type IX, P-6141; Sigma) in $2 \mathrm{ml}$ of ASW [ $460 \mathrm{~mm} \mathrm{NaCl}, 10 \mathrm{~mm}$ $\mathrm{KCl}, 10 \mathrm{mM} \mathrm{CaCl}_{2}, 48 \mathrm{~mm} \mathrm{MgCl}_{2}$, and $10 \mathrm{~mm}$ HEPES (H-3375; Sigma), $\mathrm{pH}$ 7.8] for $1 \mathrm{hr}$ at $36^{\circ} \mathrm{C}$ before desheathing at room temperature. A desheathed ganglion was pinned down on a sylgard dish (1 inch in diameter) and superfused with ASW (20-25 ml) containing varying concentrations of SNC, 8-Br-cGMP, or histamine (flow rate, $2.5-3 \mathrm{ml}$ / $\mathrm{min}$ ) to measure the subthreshold membrane depolarization and increase in input resistance of the $\mathrm{MCC}$ in response to each drug. Intracellular recording micropipettes $(10-20 \mathrm{M} \Omega$ ) were filled with $3 \mathrm{M}$ potassium acetate and $0.1 \mathrm{M} \mathrm{KCl}$. The membrane depolarization and change in input resistance were recorded immediately after the end of the superfusion (8-10 $\mathrm{min})$. Input resistance was measured as the voltage deflection caused by a -0.5 or $-1.0 \mathrm{nA}$ current pulse $(1 \mathrm{sec})$. The vsEPSP in the MCC was evoked by stimulating $\mathrm{C} 2$ with a $2-3$ sec current pulse (2-4 $\mathrm{nA})$ injection, resulting in a train of action potential spikes. The firing frequency of $\mathrm{C} 2$ during stimulation was moderately stable most of the time in each individual animal. Because of the tendency to facilitate, the vsEPSPs were measured with at least 5 min breaks for recovery to the normal state before subsequent stimulations.

cGMP immunocytochemistry. Isolated and desheathed cerebral ganglia pinned down on separate dishes $(2 \mathrm{ml}$ volume) were pretreated for 30 min with $1 \mathrm{mM}$ IBMX in ASW and treated for 2 min with ASW containing varying concentrations of SNC, histamine, or degassed SNC in the presence of $1 \mathrm{mM}$ IBMX. When used, the sGC inhibitor (ODQ or LY83583) was included in the IBMX pretreatment solution as well as in the actual SNC or histamine treatment solution. Immediately after the treatment, $4 \%$ paraformaldehyde in $0.1 \mathrm{~m}$ sodium phosphate, $\mathrm{pH} 7.4$, was added to each dish for overnight fixation $\left(4^{\circ} \mathrm{C}\right)$. After a wash in $0.5 \%$ Triton X-100 in PBS, pH 7.4 (PBST), the ganglia were incubated with $1.5 \%$ normal rabbit serum (R-9133; Sigma) in PBST for $5 \mathrm{hr}$ and then with a 1:20,000 dilution of anti-cGMP sheep antiserum (gift from Dr. Jan De Vente, University of Limburg) in PBST overnight. After being washed in PBST, they were incubated with a 1:2000 dilution of peroxidase-conjugated anti-sheep or -goat rabbit antiserum (A-5420; Sigma) and $1.5 \%$ normal rabbit serum in PBST for $2 \mathrm{hr}$, followed by another wash in PBST. The ganglia were then pinned down in a glass dish for peroxidase reaction with 3,3'-diaminobenzidine (DAB) substrate solution (peroxidase substrate kit, SK-4100; Vector Laboratories, Burlingame, CA). Color-developed ganglia were dehydrated with an ethanol series $(50,75,95$, and $100 \%)$, cleared in xylene, and mounted on slide glasses with Permount (SP15-100; Fisher Scientific). Each step was done at room temperature except fixation $\left(4^{\circ} \mathrm{C}\right)$. The relative optical density of the MCC was measured using a Metamorph video imaging software (Universal Imaging Corporation, West Chester, PA) (gray levels $0-256$ ), with background density being measured as an average of the densities of three unstained nearby cells.

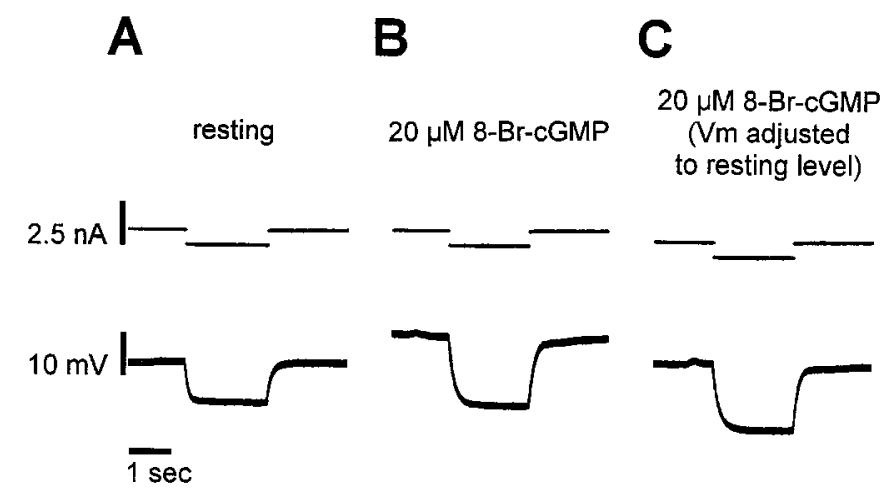

Figure 1. A representative recording of the membrane response of the MCC to 8-Br-cGMP. Input resistance was measured with one electrode as the size of voltage deflection caused by a negative current pulse $(-1.0 \mathrm{nA}$; $2 \mathrm{sec}$ ) injection into the cell with another electrode. $A$, The membrane potential $(-68 \mathrm{mV})$ and input resistance $(9 \mathrm{M} \Omega)$ at resting are shown. $B$, 8-Br-cGMP $(20 \mu \mathrm{M})$ depolarized the MCC membrane by $\sim 8 \mathrm{mV}$ and increased the input resistance by $\sim 88 \%$ of the control value. $C$, The increase in input resistance, seen in $B$, was unchanged when the membrane potential was adjusted to the resting level by negative DC current injection.

\section{RESULTS}

\section{8-Br-cGMP mimics the response of the MCC to an NO generator, SNC}

NO released from exogenous NO-donor compounds, such as SNC and SIN-1, mimics the membrane depolarization and increase in input resistance that are characteristic of the vsEPSP that occurs in the MCC during stimulation of NOS-containing neuron C2 (Jacklet, 1995). Because the most common effector of NO identified in many CNS tissues is sGC, the enzyme that synthesizes cGMP, and preliminary evidence (Koh and Jacklet, 1997) suggested sGC was involved, we sought evidence that the effects of bath-applied NO donors on the MCC membrane are mediated by cGMP. Bath application of the 8-Br-cGMP (a membranepermeable and nonhydrolyzable analog of cGMP) to the cerebral ganglion containing the MCC mimicked the response to bathapplied SNC. As shown in Figure 1, 8-Br-cGMP induced the characteristic membrane depolarization and increase in membrane input resistance. Repolarizing the membrane potential to the resting level with applied current showed that the increase in input resistance was not caused by the shift in membrane potential. The time course of the responses to 8-Br-cGMP was similar to that of the effects of SNC [reaching final values $\sim 10$ min after the start of superfusion (Jacklet, 1995)]. Without washout, the SNC effects slowly faded away in a few hours, consistent with the expected reduction in NO generation with time, whereas the effects of nonhydrolizable 8-Br-cGMP lasted for many hours without reduction.

The compounds were tested over a range of doses (Fig. 2) to make a quantitative comparison of the MCC responses. When cerebral ganglion was superfused with ASW containing SNC $(10-200 \mu \mathrm{M})$, the membrane depolarized and input resistance increased in a dose-dependent way. These responses reached the threshold for spike initiation in the MCC (depolarization by $\sim 10$ $\mathrm{mV}$ and $\sim 90 \%$ increase in input resistance; Fig. $2 A$ ) at $\sim 100 \mu \mathrm{M}$ SNC. The MCC response to 8-Br-cGMP (5-100 $\mu \mathrm{M})$ was also dose dependent (Fig. $2 B$ ), and the membrane potential reached spike threshold at approximately the same level ( $\sim 10 \mathrm{mV}$ depolarization and $\sim 120 \%$ increase in input resistance). The response 
A B
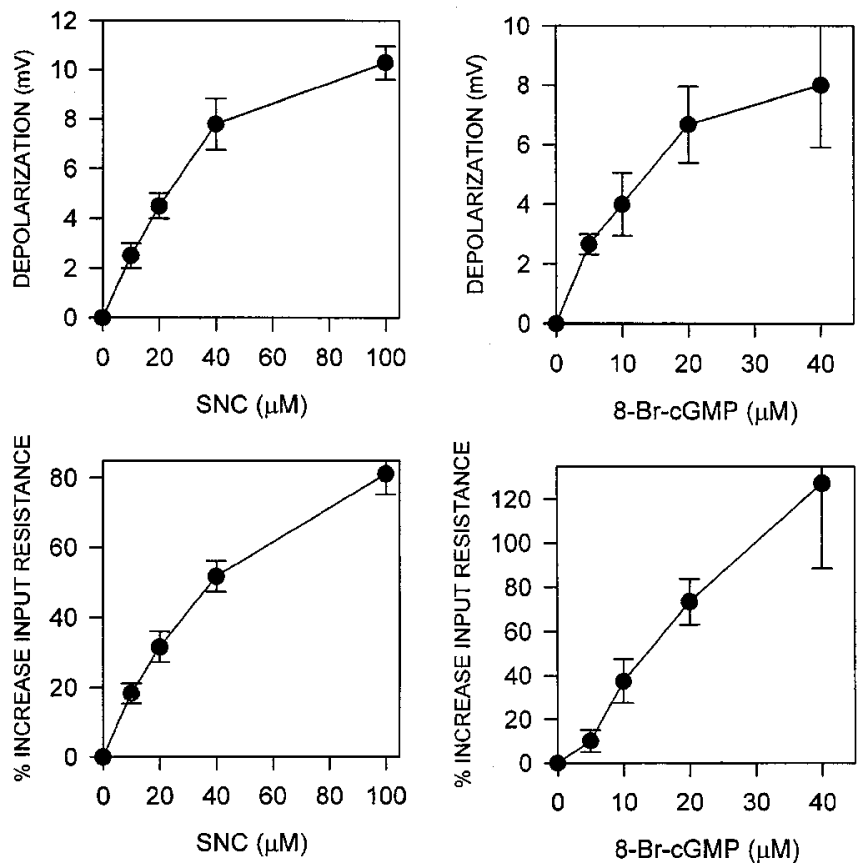

Figure 2. MCC membrane responses to the $\mathrm{NO}$ generator $\mathrm{SNC}$ and to 8-Br-cGMP. Changes in membrane potential and input resistance were measured during superfusion of the ganglion with ASW containing various concentrations of either drug at a flow rate of $3 \mathrm{ml} / \mathrm{min}$. Each point with error bar represents a mean \pm SE. Top graphs, Depolarization from the resting potential. Bottom graphs, Percent increase in input resistance, calculated from the voltage deflection caused by a 1 sec negative current pulse (see Fig. 1). The resting membrane potential and input resistance were usually $-70 \mathrm{mV}$ and 6-7 $\mathrm{M} \Omega$, respectively. $A$, Dose responses to

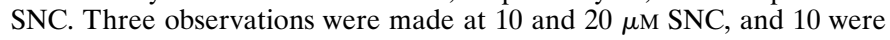
made at 40 and $100 \mu \mathrm{M}$ SNC in 10 preparations. $B$, Dose responses to 8-Br-cGMP. Three observations were made at 5 and $40 \mu \mathrm{M} 8-\mathrm{Br}-\mathrm{cGMP}$, five were made at $10 \mu \mathrm{M} 8$-Br-cGMP, and six were made at $20 \mu \mathrm{M}$ 8-Br-cGMP in six preparations. At higher doses than those on the graphs, the membrane potential reached the action potential threshold, so measurements of depolarization and input resistance were unreliable.

to $100 \mu \mathrm{M}$ SNC was approximately equivalent to the response to $40 \mu \mathrm{M}$ 8-Br-cGMP. 8-Br-cAMP and 8-Br-GMP (10-100 $\mu \mathrm{M}$ for each one) were used as controls for the specificity of 8-Br-cGMP effects. They had essentially no effect on the membrane of the MCC $(0.67 \pm 0.82 \mathrm{mV}$ depolarization and $0 \pm 0 \%$ increase in input resistance for $40 \mu \mathrm{M} 8$-Br-GMP; $n=3 ; 0.33 \pm 0.58 \mathrm{mV}$ depolarization and $0 \pm 0 \%$ increase in input resistance for $40 \mu \mathrm{M}$ 8-Br-cAMP; $n=3$ ).

\section{ODQ and LY83583 suppress the vsEPSP in the MCC}

The results above show that 8 -Br-cGMP mimics the MCC membrane responses that are characteristic of the responses to $\mathrm{NO}$ donors and the vsEPSP evoked by $\mathrm{C} 2$ stimulation. This suggested that the portion of the vsEPSP induced by the cotransmitter NO is mediated by elevation of intracellular cGMP level via activation of sGC. To examine this further, we tested the effects of two membrane-permeable inhibitors of sGC, ODQ and LY83583, on the vsEPSP produced by the firing of $\mathrm{C} 2$.

The vsEPSP, as its name suggests, rises and decays very slowly. The typical speed of depolarization in the MCC vsEPSP induced by a train of $\mathrm{C} 2$ spikes (Fig. 3) at 10-20 spikes/sec is $\sim 2-5$ $\mathrm{mV} / \mathrm{sec}$. It starts to decay at approximately one-half a second after the end of $\mathrm{C} 2$ firing. If the duration of $\mathrm{C} 2$ activation is long enough and the frequency high enough, the depolarization reached spike threshold at $\sim 10 \mathrm{mV}$ above resting potential. The C2 firing rate for a constant current of stimulation was stable through several hours of experimentation, if 10-20 spikes/sec firing for 2-3 sec was used to evoke the vsEPSP. At least a $3 \mathrm{~min}$ rest between trials was required for the vsEPSP to recover to its original size.

When the cerebral ganglion was superfused with ASW containing ODQ $(20 \mu \mathrm{M})$ or LY83583 $(5 \mu \mathrm{M})$, the vsEPSP was reduced to approximately one-half of its normal amplitude (Fig. $3 A, B)$. Partial block was expected, because the vsEPSP is thought to be partly mediated by the cotransmitter histamine (Jacklet, 1995). Preliminary dose experiments revealed the lowest effective doses of ODQ and LY83583 needed to get maximum suppression of the vsEPSP. Maximum suppression was obtained with $10 \mu \mathrm{M}$ ODQ and $3 \mu \mathrm{M} \mathrm{LY83583,} \mathrm{so} \mathrm{to} \mathrm{be} \mathrm{safe} \mathrm{a} \mathrm{slightly} \mathrm{higher} \mathrm{dose} \mathrm{was}$ used as a standard dose. Monitoring the vsEPSP at $5 \mathrm{~min}$ intervals revealed that there was no further change in the vsEPSP after 50 min of drug treatment. The vsEPSP was reduced to approximately one-half in the presence of $20 \mu \mathrm{M}$ ODQ $(48.6 \pm 2.48 \%$ of control; $p<0.0001 ; n=7$; paired $t$ test), and after washout for $1-2 \mathrm{hr}$ with ASW, the vsEPSP partially $(80.1 \pm 4.75 \% ; n=7)$ recovered (Fig. $3 A$ ) or occasionally did not recover at all. There was a similar pattern of the vsEPSP size reduction with $5 \mu \mathrm{M}$ LY83583 (45.9 $\pm 3.13 \%$ of control; $p<0.0001 ; n=11)$. The vsEPSP always fully recovered to its control size $(91.7 \pm 2.89 \%$; $n=11$ ) after $30-40 \mathrm{~min}$ of washout (Fig. $3 B$ ). The suppressive effects of these sGC inhibitors on the vsEPSP support our hypothesis that the NO-induced portion of the vsEPSP is mediated by the sGC-cGMP pathway.

\section{ODQ and LY83583 block the membrane response to SNC but not the response to histamine}

We hypothesize that the vsEPSP in the MCC is composed of two distinct components, a histamine-induced component not mediated by sGC and an NO-induced component mediated by sGC, because there was a consistent partial suppression of the vsEPSP by the two sGC inhibitors (Fig. 3) and because the bath application of histamine and SNC together seemed to result in a simple additive depolarization and increase in input resistance (H.-Y. Koh and J. W. Jacklet, unpublished observations). This hypothesis was further tested by comparing the abilities of the sGC inhibitors to block the MCC's membrane responses to either histamine or SNC.

The cerebral ganglion was pretreated with $5 \mu \mathrm{M}$ LY83583 for $30 \mathrm{~min}$, and the suppression of the vsEPSP was monitored regularly (at 5 min intervals) until there was not further change. This confirmed the suppressive activity of LY83583 before either SNC or histamine. Then the membrane depolarization and change in input resistance caused by either SNC (10-100 $\mu \mathrm{M})$ or histamine (0.05-0.25 mM) were measured in the presence of LY83583 and compared with the control values. The SNC response was reduced by $5 \mu \mathrm{M} \mathrm{LY83583} \mathrm{to} \mathrm{approximately} \mathrm{one-third}(33.1 \pm$ $3.48 \%$ for depolarization; $n=8 ; p<0.0001 ; 25.4 \pm 7.13 \%$ for the increase in input resistance; $n=8 ; p<0.005$; paired $t$ test). The 


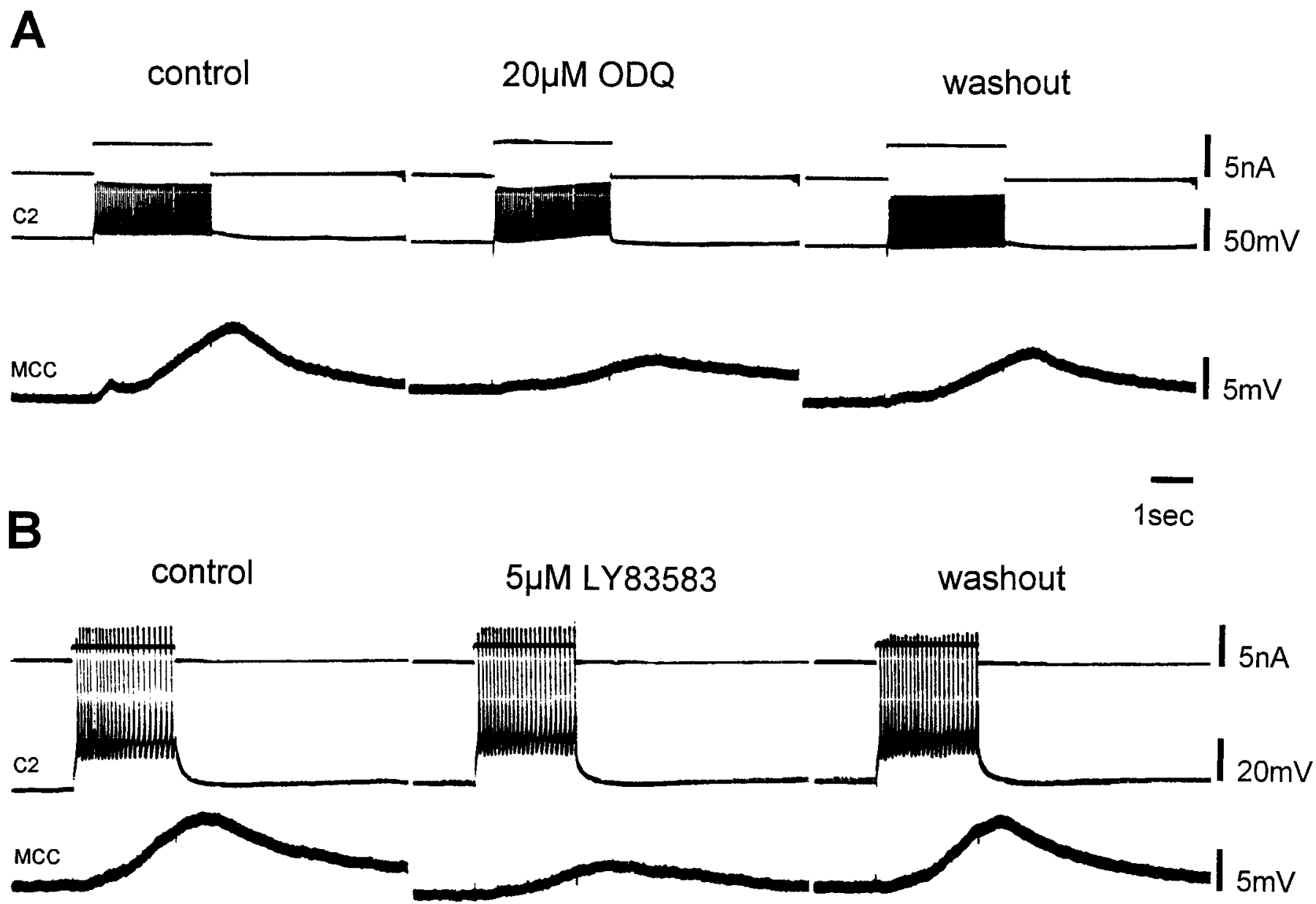

Figure 3. Effects of sGC inhibitors (ODQ and LY83583) on the vsEPSP evoked in the MCC by C2 stimulation. An isolated cerebral ganglion was superf used with ASW containing either drug at the flow rate of $3 \mathrm{ml} / \mathrm{min}$. $A$, ODQ $(20 \mu \mathrm{M})$ reduced the vsEPSP size to $44.4 \%$ of the control value. The change was complete $40 \mathrm{~min}$ after the start of superfusion with ODQ. After washout for 90 min, the vsEPSP partially recovered ( $\sim 75 \%)$. $B$, LY83583 $(5 \mu \mathrm{M})$ reduced the vsEPSP size to $43 \%$ in $30 \mathrm{~min}$. After washout for $60 \mathrm{~min}$, it recovered fully.

MCC response to histamine was unaffected $(117 \pm 11.2 \%$ for depolarization; $n=5 ; p=0.2420 ; 109 \pm 6.06 \%$ for the increase in input resistance; $n=4 ; p=0.1915)$. The incomplete suppression of SNC responses by LY83583 suggests that $5 \mu \mathrm{M} \mathrm{LY83583}$ could not block all the sGC enzymes or that the unsuppressed part of the NO effect is mediated by another second messenger. Because nonspecific effects of LY83583 have been reported (Mulsch et al., 1988; Barbier and Lefebvre, 1992), we tested another sGC inhibitor to see whether we could obtain greater suppression of the SNC response. ODQ, unlike LY83583 and another nonspecific inhibitor, methylene blue, is known to be quite specific for NO-stimulated sGC activity. It has no effect on other nucleotide cyclases, NOS activity, or NO (Garthwaite et al., 1995). The effects of ODQ on the MCC membrane responses to SNC and to histamine were examined in the same way as in the experiments with LY83583. There was almost complete blockage of the SNC response by $20 \mu \mathrm{M}$ ODQ (Fig. $4 A$ ) and little or no effect on the histamine response (Fig. $4 B$ ). These results suggest that the exogenous NO effect in this cell is mediated mainly by activation of sGC and further suggest that ODQ suppresses the vsEPSP by inhibiting an NO-induced reaction and not a histamine-related mechanism.
SNC, but not histamine, increases cGMP-IR in the MCC in a dose-dependent manner

To determine whether cGMP is indeed synthesized in the MCC in response to NO, we determined cGMP production by wholemount cGMP-IR after bath application of SNC. In cGMP-IR, cGMP produced by the chemical or physiological treatment of tissues is fixed to the protein matrix of the cell by paraformaldehyde treatment of the tissue, and then an antiserum against formaldehyde-fixed cGMP is used for immunodetection (De Vente and Steinbusch, 1993).

In the presence of $1 \mathrm{mM}$ IBMX, SNC increased cGMP-IR in the MCC. Representative immunoreactive neurons in Figure $5 A-D$ show that the staining intensity increased in proportion to the dose of SNC used. The results of the all the cGMP-IR experiments were quantified using optical density measurements, and the summary graphs of the data from Figure 5 and similar experiments are shown in Figure 6. Figure $6 A$ shows the SNC dose dependence. The minimal dose for full staining for a $2 \mathrm{~min}$ exposure was $100 \mu \mathrm{M}$. There was no substantial staining of the MCC in the ganglia treated either with IBMX alone or with 100 $\mu \mathrm{M}$ SNC that was degassed overnight (Fig. $5 E$ ). Without IBMX in combination with SNC, SNC did not induce cGMP-IR, i.e., 


\section{A B}
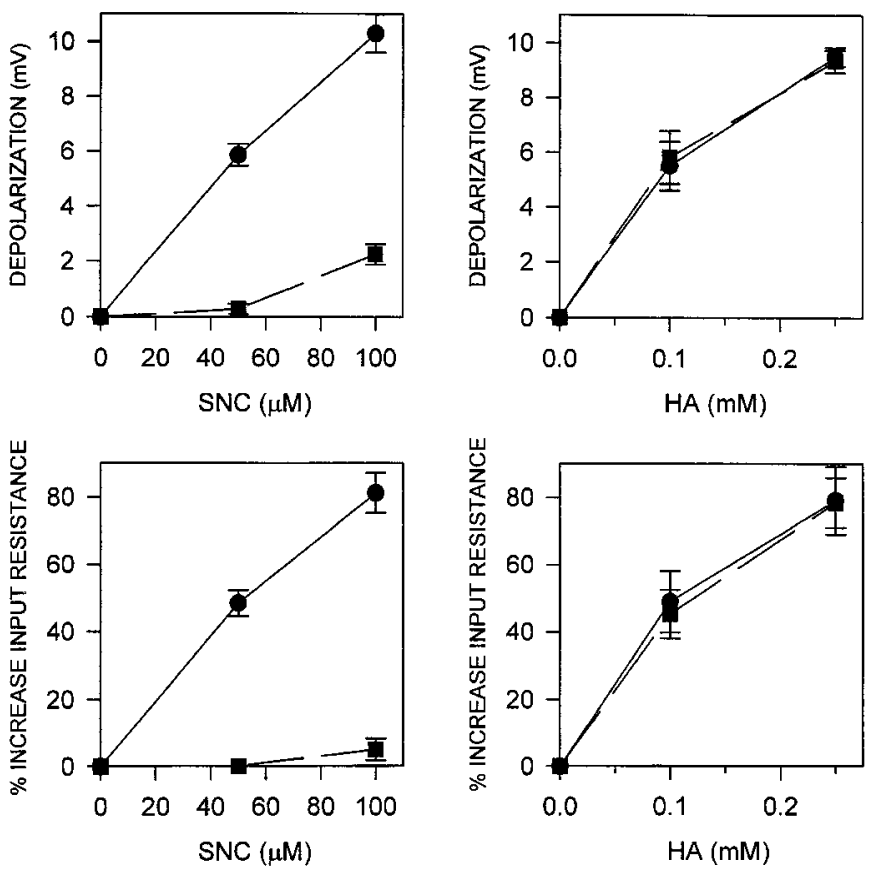

Figure 4. Effects of ODQ on the responses to SNC and to histamine $(H A)$ in the MCC. $A$, The response to SNC in the presence of $20 \mu \mathrm{M}$ ODQ was measured by superfusing the preparation with ASW containing both SNC and ODQ after the effect of ODQ pretreatment reached a plateau. Circles are control responses (absence of ODQ), and squares are experimental responses (presence of $20 \mu \mathrm{M}$ ODQ). Input resistance was measured as the size of the voltage deflection caused by a $-1.0 \mathrm{nA}$ current pulse ( $1 \mathrm{sec})$ to the cell ( $n=7$ and 6 for 50 and $100 \mu \mathrm{M} \mathrm{SNC}$, respectively). $B$, The response to $H A$ in the presence of ODQ was measured as described in $A$ ( $n=8$ and 6 for 0.1 and $0.25 \mathrm{~mm} H A$, respectively). The control responses to SNC and to $H A$ in the absence of ODQ were recorded before the pretreatment with ODQ. Each point represents a mean $\pm \mathrm{SE}$.

ganglia were not different from untreated ganglia. A group of three to five unidentified tiny cells $(<20 \mu \mathrm{m}$ in diameter) located between the bases of cerebropedal and cerebropleural connectives was consistently stained by the antiserum, regardless of the SNC treatment. Staining of these cells was so reliable that it was an indicator of a successful immunocytochemical procedure. A few other groups of cells in the cerebral ganglion were stained after SNC treatment, but the results are not presented here. Histamine $(250 \mu \mathrm{M})$ did not induce immunostaining (Fig. $5 F)$ at the dose that caused the maximum depolarization and increase in input resistance. This result is consistent with the failure of sGC inhibitors to suppress the MCC's membrane response to histamine (Fig. 4B).

cGMP-IR in the MCC resulting from treatments of various durations (0-20 min) of exposure to $100 \mu \mathrm{M}$ SNC was examined (Fig. 5G-L). This allowed us to determine an optimal SNC treatment time for cGMP-IR. The highest density was observed in durations between 2 and 5 min (Figs. $5 I, J, 6 B$ ), so all other cGMP-IR experiments were done with a 2 min SNC treatment.

\section{ODQ blocks NO-induced cGMP-IR in the MCC in a dose-dependent manner}

The involvement of the sGC-cGMP system in NO signaling in the MCC was further tested by determining whether the $\mathrm{sGC}$ inhibitors block the cGMP-IR in the MCC induced by SNC application. The cGMP-IR induced by $100 \mu \mathrm{M}$ SNC was suppressed by ODQ in a dose-dependent way (Fig. 5M-O). It was almost completely blocked by $10 \mu \mathrm{M}$ ODQ (Fig. 5O). Quantification of the results of all ODQ experiments shows a clear proportionality between ODQ dose and block of the cGMP-IR (Fig. $6 C)$. This further supports the hypothesis that NO acts by stimulating sGC and consequently increasing cGMP in the MCC.

\section{DISCUSSION}

Soluble GC is known as a major target protein for NO in the CNS (Luo et al., 1994). NO activates sGC and promotes the increase in intracellular cGMP level by binding to the heme moiety with high affinity (Taylor and Sharma, 1992). Soluble GC and cGMP were thought to be involved in the second messenger pathway for NO action in the MCC because a previous study showed that the vsEPSP was partially suppressed by methylene blue, a nonspecific GC inhibitor (Jacklet and Gruhn, 1994), and preliminary evidence had shown that 8 -Br-cGMP induced the membrane responses that are characteristic of the vsEPSP and the responses to SNC (Koh and Jacklet, 1997). Our present dose-response results show that the 8-Br-cGMP-induced membrane depolarization and increase in input resistance closely parallel the effects of SNC. Like the SNC results (Jacklet, 1995), the increase in input resistance induced by 8 -Br-cGMP persists whenever the membrane potential is repolarized to the resting level, so it is independent of the membrane potential. The depolarization resulting from either 8-Br-cGMP or SNC treatment is consistent with the idea that they cause closure of potassium channels, and the membrane potential shifts away from the potassium equilibrium potential, in the depolarizing direction, as a result.

The present study shows that two specific sGC inhibitors (ODQ and LY83583) suppress both the vsEPSP and the membrane responses to $\mathrm{SNC}$ in the MCC. We found that even supramaximal doses of these sGC inhibitors always partially suppressed the vsEPSP, to $\sim 45 \%$. Partial vsEPSP suppression has also been observed in the previous experiments using the NOS inhibitor L-NAME (Jacklet, 1995). These results combined with the inability of sGC inhibitors to suppress the histamine response support the idea that the vsEPSP is mediated by both the NO-sGCcGMP and histamine pathways in approximately equal portions, at least within the range of $\mathrm{C} 2$ spike activity used here. Further determination of the proportion of the vsEPSP that is contributed by each pathway could be made if the histamine pathway could be blocked by histamine receptor antagonists. A previous attempt to block the vsEPSP in $\mathrm{C} 4$, another $\mathrm{C} 2$ follower, with histamine antagonists was unsuccessful (McCaman and Weinreich, 1985), although $\mathrm{H} 1$ and $\mathrm{H} 2$ histamine receptor antagonists did block fast histamine responses in other $\mathrm{C} 2$ follower neurons in the cerebral ganglion. The latter observation provides further support for the idea that $\mathrm{C} 2$ does release histamine at its synapses.

The membrane input resistance and the depolarization in response to SNC were reduced to $\sim 25$ and $33 \%$, respectively, by LY83583, but not completely blocked, whereas the ODQ block was virtually complete. This difference is presumed to be caused by the additional action of LY83583 on other activities, such as NOS (Mulsch et al., 1988). The specific action of ODQ was shown in studies on rat cerebellar slices. Garthwaite et al. (1995) found that $1 \mu \mathrm{M}$ ODQ reduced NO-induced cGMP accumulation to $\sim 12.5 \%$, and $10 \mu \mathrm{M}$ ODQ completely blocked the NO-induced enzyme activity of purified sGC. 

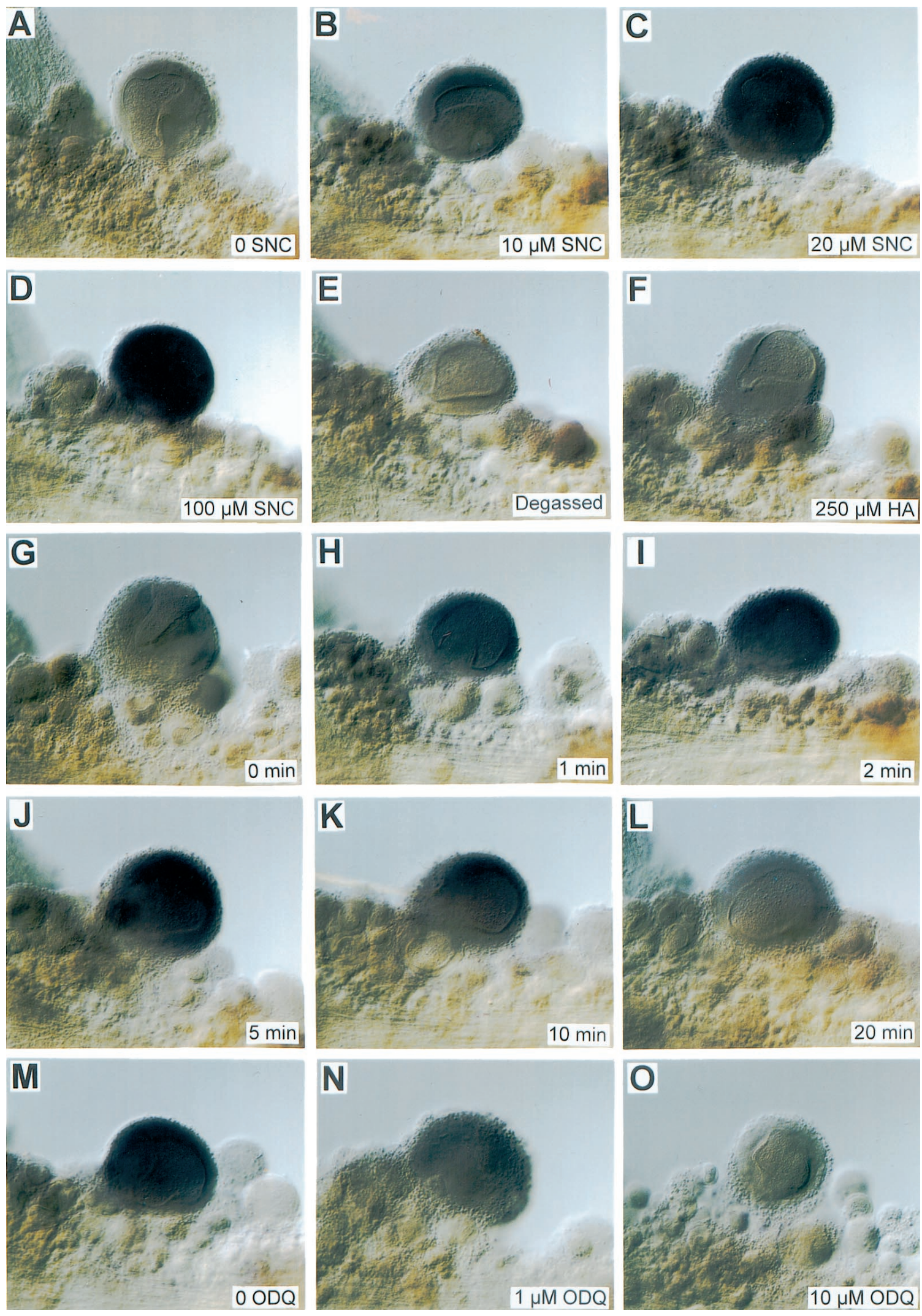

Figure 5. cGMP-IR in the MCC induced by exposure to SNC at several concentrations and times and during inhibition by ODQ. The huge cell body (150-200 $\mu \mathrm{m}$, diameter) at the center of each photograph is the MCC. $A-D$, cGMP-IR induced by treatment for 2 min with increasing doses of SNC. $E$, Treatment for 2 min with $100 \mu \mathrm{M}$ SNC that was degassed overnight. $F$, Treatment for 2 min with $250 \mu \mathrm{M}$ histamine $(H A)$. $G-L$, The time dependence of cGMP-IR in the MCC induced by $100 \mu \mathrm{M}$ SNC. Note the decreased staining intensity after $10 \mathrm{~min}$. $M-O$, The effect of increasing ODQ concentration on the NO-induced cGMP-IR in the MCC. Note that $10 \mu \mathrm{M}$ ODQ almost completely blocked the cGMP-IR in the MCC $(O)$. 


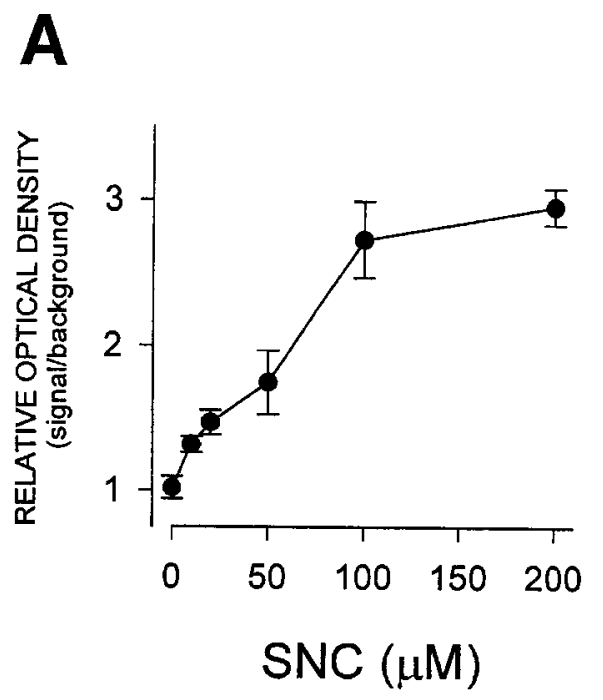

\section{B}

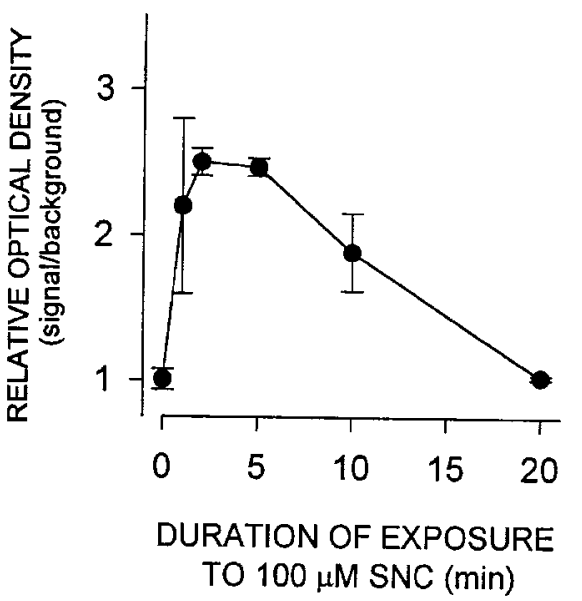

C

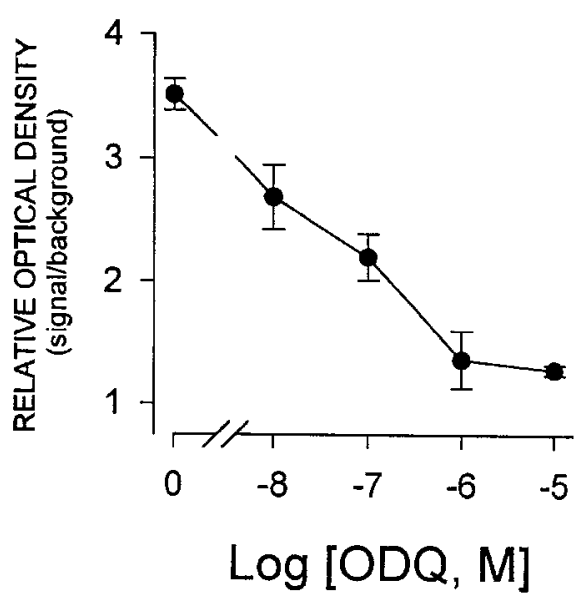

Figure 6. Summary of SNC-induced cGMP-IR in the MCC. The relative optical density of staining was measured using a Metamorph video imaging system (background density was measured as an average of the densities of three unstained nearby cells). Each point in the graphs represents a mean \pm SE. Data were collected from three sets of experiments for all three graphs. $A$, Dose dependency of cGMP-IR induced by SNC (0-200 $\mu \mathrm{M}$ for 2 min). $B$, cGMP-IR induced by $100 \mu \mathrm{M}$ SNC for durations of $0-20 \mathrm{~min}$. $C$, Dose-dependent inhibition by ODQ (10 nM to $10 \mu \mathrm{M})$ of cGMP-IR induced by SNC $(100 \mu \mathrm{M}$ for $2 \mathrm{~min})$.

The SNC-induced cGMP-IR in the MCC increased in proportion to the SNC dose, and the response profile was similar to the membrane responses to SNC. The cGMP-IR in the MCC was progressively suppressed by increasing doses of ODQ and completely blocked at the dose that inhibits the SNC membrane responses almost completely. These results are consistent with the hypothesis that the membrane responses induced by SNC (NO) are the outcome of an increase in intracellular cGMP level in the MCC. In addition, the inability of histamine to induce cGMP-IR in the MCC and the inability of sGC inhibitors to block the membrane response to histamine imply a separate and distinct second messenger pathway for histamine in the MCC.

Most of the cGMP-IR disappeared after $10 \mathrm{~min}$ of SNC treatment, suggesting that either the cGMP molecules are not produced for $>5-10$ min or there is another cGMP-quenching system that is not inhibited by IBMX in this system. This is unlike many other studies in which substantial cGMP-IR was obtained after 15 min treatments with $\mathrm{NO}$ generators in the presence of IBMX [crab stomatogastric nervous system (Scholz et al., 1996); guinea pig intestine (Young et al., 1993); rat brain slices (De Vente and Steinbusch, 1993); and Drosophila neurons (Gibbs and Truman, 1998)]. This response timing is unexplained, but it seems most likely that the MCC has a strong cGMP-quenching mechanism.

Several unsuccessful attempts were made to induce cGMP-IR in the MCC by synaptic activation provoked by electrically stimulating $\mathrm{C} 2$. The cell body of the MCC did not stain, and any stain along the neurite was not detectable. The synaptic contacts from $\mathrm{C} 2$ are not on the MCC cell body but likely occur along the neurite at $>400 \mu \mathrm{m}$ from the cell body, deep within the ganglion. Successful detection of a synaptically induced increase in cGMP-IR will likely require a precise anatomical localization of the synaptic contacts by dye marking the terminals, deep tissue detection using confocal microscopy, and rapid fixation to allow for the short duration of the enhanced cGMP-IR. An additional complication is that, although the NO release sites are presumed to be at the synaptic terminals of $\mathrm{C} 2$, they are not known.
The vsEPSP in the MCC seems to be mediated by the closing of a potassium channel (Weiss et al., 1986a). Under voltage clamp, the current-voltage relationship curve was shifted in the inward direction with a decrease in slope conductance by bathapplied histamine. This histamine-induced shift disappears at approximately $-80 \mathrm{mV}$, the normal equilibrium potential for potassium, but did not reverse. The potential at which the histamine-induced $I-V$ shift disappeared was dependent on the external $\mathrm{K}^{+}$concentration. This evidence supports the notion that the vsEPSP is caused by a decrease in $\mathrm{K}^{+}$conductance caused by histamine released from C2 (Weiss et al., 1986a). The similarity of the SNC responses to the histamine responses (depolarization and decrease in membrane conductance) suggests that $\mathrm{K}^{+}$channels are closed in each response. It will be interesting to find out in later experiments whether $\mathrm{NO}$ and histamine affect distinct $\mathrm{K}^{+}$channels or converge on the same ones and whether NO-induced cGMP acts directly on $\mathrm{K}^{+}$channels or via protein phosphorylation mediated by a protein kinase.

NO depolarizes the MCC by reducing a resting membrane potassium conductance, and this effect is mimicked by $8-\mathrm{Br}-$ cGMP. Some neurons in the abdominal ganglion of another species (Aplysia kurodai) are depolarized by either NO or cGMP (Sawada et al., 1995), but the effect is produced by increasing sodium conductance. This difference in ionic conductance changes is not too surprising because cGMP is known to be coupled to a variety of ion channel types. In the mammalian PNS, NO causes smooth muscle relaxation by increasing potassium conductance (Thornbury et al., 1991) and thereby hyperpolarizing the membrane potential. NO seems to have a variety of actions on membrane ion channels.

Neuron $\mathrm{C} 2$ is a mechanoafferent neuron that conveys sensory information from the mouth of Aplysia to the neural circuit for feeding. It contributes to the maintenance of food arousal (Weiss et al., 1986b) by means of its synaptic connection to the MCC and other neurons of the feeding circuit. The MCC is usually silent, but after it is activated by food stimuli or other sensory inputs, it contributes to the food arousal state (Kupfermann and Weiss, 
1982) by potentiating the consummatory aspects of feeding behavior via both peripheral and central actions (Weiss et al., 1978; Rosen et al., 1989). C2 activation produces arousal effects that outlast the stimulus in part via its vsEPSP connection to the MCC, which may last for $10 \mathrm{sec}$ or more after $\mathrm{C} 2$ stops firing, and in part via long-lasting modulation of the feeding circuit by the MCC's serotonergic output (Weiss et al., 1986b). The vsEPSP seems to be mediated by both histamine and NO from our previous work (Jacklet, 1995; Koh and Jacklet, 1997) and the results of the present experiments. We find that the vsEPSP retains its longlasting characteristic after the amplitude is reduced to one-half by treatment with either soluble GC inhibitors or NOS inhibitors. Therefore NO is not solely responsible for the long-lasting character of the vsEPSP. Histamine synaptic responses are known to be slow, particularly if they are mediated by a second messenger pathway involving a G-protein ( $\mathrm{Li}$ and Hatton, 1996).

Our finding that NO seems to be used as a cotransmitter with histamine in $\mathrm{C} 2$ serves as an example of what might be found in other systems. NO may serve as a cotransmitter or modulator in many systems, because NOS is commonly colocalized in presynaptic neurons with a conventional transmitter. For example, in the cerebellum NOS is found in granule cells along with glutamate and in basket cells along with GABA (Vincent, 1986). Also, in the gastropod Pleurobranchia, NOS is colocalized with serotonin in the giant cerebral neurons (Moroz and Gillette, 1996).

The morphological and functional homologs of paired serotonergic cerebral giant neurons in the gastropods Aplysia, Helix, Lymnaea, and Pleurobranchaea have been extensively studied at both the physiological and behavioral levels (e.g., Yeoman et al., 1994). They have similar but not identical characteristics. Relevant to this study, the MCC in Aplysia does not stain using NADPH diaphorase (Jacklet and Gruhn, 1994), although 30 paired cerebral ganglion neurons, including $\mathrm{C} 2$, do. Therefore, the MCC apparently does not contain NOS, and a hypothetical synaptic stimulation of NOS in the MCC by histamine-induced depolarization and calcium influx with subsequent NO autostimulation of cGMP production is ruled out. The cerebral giant neurons of Helix do not stain after either NADPH-diaphorase or cGMP-IR treatment (Huang et al., 1998), but some other central neurons do stain after each treatment. The cerebral giant cell (CGC) of Lymnaea, the pond snail, was not stained using NADPH-diaphorase histochemistry (Elphick et al., 1995), but a few central neurons and many sensory fibers did. However, CGC is labeled by an in situ hybridization antisense probe for LymnNOS (Korneev et al., 1998), suggesting that it does contain that Lymnaea form of NOS. The giant cerebral neuron of Pleurobranchaea does stain after NADPH-diaphorase treatment (Moroz and Gillette, 1996) and presumably contains an NOS-like molecule. Clearly, more information is needed to clarify the comparative aspects of NOS localization and function in gastropod cerebral giant neurons. The MCC contains sGC and responds to NO with cGMP-IR.

\section{REFERENCES}

Barbier AJ, Lefebvre RA (1992) Effect of LY 83583 on relaxation induced by non-adrenergic non-cholinergic nerve stimulation and exogenous nitric oxide in the rat gastric fundus. Eur $\mathrm{J}$ Pharmacol 219:331-334.

Bredt DS, Snyder SH (1994) Nitric oxide: a physiologic messenger molecule. Annu Rev Biochem 63:175-195.

Chiel HJ, Weiss KR, Kupfermann I (1986) An identified histaminergic neuron modulates feeding motor circuitry in Aplysia. J Neurosci 6:2427-2450.

Chiel HJ, Weiss KR, Kupfermann I (1990) Multiple roles of a histaminergic afferent neuron in the feeding behavior of Aplysia. Trends Neurosci 13:223-227.

De Vente J, Steinbusch HWM (1993) Immunocytochemistry of second messenger molecules: the study of formaldehyde-fixed cyclic GMP. In: Immunocytochemistry II (Cuello AC, ed), pp 409-427. New York: Wiley.

Elphick M, Kemenes G, Staras K, O'Shea M (1995) Behavioral role for nitric oxide in chemosensory activation of feeding in a mollusc. J Neurosci 15:7653-7664.

Garthwaite J (1991) Glutamate, nitric oxide and cell-cell signaling in the nervous system. Trends Neurosci 14:60-67.

Garthwaite J, Southam E, Boulton CL, Nielsen EB, Schmidt K, Mayer B (1995) Potent and selective inhibition of nitric oxide-sensitive guanylyl cyclase by $1 \mathrm{H}-[1,2,4]$ oxadiazolo[4,3-a]quinoxalin-1-one. Mol Pharmacol 48:184-188.

Gibbs S, Truman J (1998) Nitric oxide and cyclic GMP regulate retinal patterning in the optic lobe of Drosophila. Neuron 20:83-93.

Hope GT, Michael GJ, Knigge KM, Vincent SR (1991) Neuronal NADPH diaphorase is a nitric oxide synthase. Proc Natl Acad Sci USA 88:2811-2814.

Huang S, Kerschbaum H, Hermann A (1998) Nitric oxide-mediated cGMP synthesis in Helix neural ganglia. Brain Res 780:329-336.

Jacklet JW (1995) Nitric oxide is used as an orthograde cotransmitter at identified histaminergic synapses. J Neurophysiol 74:891-895.

Jacklet JW (1997) Nitric oxide signaling in invertebrates. Invertebrate Neurosci 3:1-14.

Jacklet JW, Gruhn M (1994) Nitric oxide as a putative transmitter in Aplysia: neural circuits and membrane effects. Neth J Zool 44:524-534.

Koh H, Jacklet JW (1997) Nitric oxide-induced cGMP-IR in the serotonergic metacerebral cell of Aplysia. Soc Neurosci Abstr 23:1234.

Korneev SA, Piper MR, Picot J, Phillips R, Korneeva EI, O'Shea M (1998) Molecular characterization of NOS in a mollusc: expression in a giant modulatory neuron. J Neurobiol 35:65-76.

Kupfermann I, Weiss KR (1982) Activity of an identified serotonergic neuron in free moving Aplysia correlates with behavioral arousal. Brain Res 241:334-337.

Lechner HA, Byrne JH (1998) New perspectives on classical conditioning: a synthesis of Hebbian and non-Hebbian mechanisms. Neuron 20:355-358.

Lei SZ, Pan Z-H, Aggarwal SK, Chen H-SV, Hartman J, Sucher NJ, Lipton SA (1992) Effect of nitric oxide production on the redox modulatory site of the NMDA receptor-channel complex. Neuron 8:10871099.

Li Z, Hatton GI (1996) Histamine-induced prolonged depolarization in rat supraoptic neurons: G-protein-mediated, $\mathrm{Ca}(2+)$-independent suppression of K+ leakage conductance. Neuroscience 70:145-158.

Luo D, Leung E, Vincent SR (1994) Nitric oxide-dependent efflux of cGMP in rat cerebellar cortex: an in vivo microdialysis study. J Neurosci 14:263-271.

McCaman RE, Weinreich D (1985) Histaminergic synaptic transmission in the cerebral ganglion of Aplysia. J Neurophysiol 53:1016-1037.

Moroz LL, Gillette R (1996) NADPH-diaphorase localization in the CNS and peripheral tissues of the predatory sea-slug Pleurobranchaea californica. J Comp Physiol [A] 367:607-622.

Müller U (1997) The nitric oxide system in insects. Prog Neurobiol 51:363-381.

Mulsch A, Busse R, Liebau S, Forstermann U (1988) LY 83583 interferes with the release of endothelium-derived relaxing factor and inhibits soluble guanylate cyclase. J Pharmacol Exp Ther 247:283-288.

Rand MJ, Li CG (1995) Nitric oxide as a neurotransmitter in peripheral nerves: nature of transmitter and mechanism of transmission. Annu Rev Physiol 57:659-682.

Rosen SC, Weiss KR, Goldstein RS, Kupfermann I (1989) The role of a modulatory neuron in feeding and satiation in Aplysia: effects of lesioning of the serotonergic metacerebral cells. J Neurosci 9:1562-1578.

Sawada M, Ichinose M, Hara N (1995) Nitric oxide induces increased $\mathrm{Na}+$ conductance in identified neurons of Aplysia. Brain Res 670:248-256.

Scholz NL, Goy MF, Truman JW, Graubard K (1996) Nitric oxide and 
peptide neurohormones activate cGMP synthesis in the crab stomatogastric nervous system. J Neurosci 16:1614-1622.

Schuman E, Madison D (1994) Nitric oxide and synaptic function. Annu Rev Neurosci 17:153-183.

Taylor TG, Sharma VS (1992) Why NO? Biochemistry 31:2837-2849.

Thornbury K, Ward S, Dalziel H, Carl A, Westfall D, Saunders K (1991) Nitric oxide and nitrocysteine mimic nonadrenergic, noncholinergic hyperpolarization in canine proximal colon. Am J Physiol 261:G553-G557.

Vincent S (1986) NADPH-diaphorase histochemistry and neurotransmitter coexistence. In: Histochemistry, modern methods and applications (Panula P, Paivrainta H, Soinila S, eds), pp 375-396. New York: Liss.

Weiss KR, Cohen JL, Kupfermann I (1978) Modulatory control of buccal musculature by a serotonergic neuron (metacerebral cell) in Aplysia. J Neurophysiol 41:181-203.
Weiss KR, Shapiro E, Kupfermann I (1986a) Modulatory synaptic actions of an identified histaminergic neuron on the serotonergic metacerebral cell of Aplysia. J Neurosci 6:2393-2402.

Weiss KR, Chiel HJ, Koch U, Kupfermann I (1986b) Activity of an identified histaminergic neuron, and its possible role in arousal of feeding behavior in semi-intact Aplysia. J Neurosci 6:2403-2415.

Weiss KR, Chiel HJ, Kupfermann I (1986c) Sensory function and gating of histaminergic neuron C2 in Aplysia. J Neurosci 6:2416-2426.

Yeoman MS, Pieneman AW, Ferguson GP, Ter Maat A, Benjamin PR (1994) Modulatory role for the serotonergic cerebral giant cells in the feeding system of the snail, Lymnaea. I. Fine wire recording in the intact animal and pharmacology. J Neurophysiol 72:1357-1371.

Young HM, McConalogue K, Furness JB, De Vente J (1993) Nitric oxide targets in the guinea-pig intestine identified by induction of cyclic GMP immunoreactivity. Neuroscience 55:583-596. 